\title{
Solar Pv Fed Grid Connected System With Reactive Power And Harmonics Compensation
}

\author{
M.Balasubramanian ${ }^{\text {a }}$, C.Priyadharshini ${ }^{\mathrm{b}}$ \\ ${ }^{a}$ Assistant Professor, ${ }^{\mathrm{b}}$ PG Scholar \\ ${ }^{\mathbf{a}, \mathbf{b}}$ Department of EEE, Government College of Engineering, Tirunelveli., India
}

Article History: Received: 10 November 2020; Revised 12 January 2021 Accepted: 27 January 2021; Published online: 5 April 2021

\begin{abstract}
The aim of this paper is to use renewable energy sources to meet the demand for electricity. For DC-AC conversion, a solar-powered three-phase grid-connected system with a boost (DC-DC) converter and three-phase inverter is used. The updated Perturb and Observe ( $\mathrm{P} \& \mathrm{O})$ Algorithm is used to map the solar photovoltaic system's maximum power point. Synchronous Reference Frame-Phase Locked Loop Theory is used to compensate for harmonic and reactive power. This proposed grid-connected system is used to improve the system's power efficiency as well as extract the full power and feed it to the distribution system. Using Matlab tools, the simulation result demonstrates reasonable efficiency.
\end{abstract}

Keywords: Maximum Power Point Tracking (MPPT), Perturb and Observe (P\&O) Algorithm, Photovoltaic (PV) array, Synchronous Reference Frame-Phase Lock Loop (SRF-PLL) theory

\section{Introduction}

Owing to the last few decades, there are enormous amount of technologies based on renewable energy sources has been implemented inaccordance of their efficient, availability, reliability and taking consideration of their affordable costs. Solar PV cells have more efficiency and available under decreased cost. Now a days nonlinear loads like laptops, LEDs are highly depends upon the power electronics devices which will causes harmonic injection into the system and lead to excess heat and noise with reactive power drop. The proposed method was used to compensate for harmonics and reactive power.

Temperature and intensity of the solar PV system depends on the sunlight radiations during day time. So there occurs some change in voltage with change in current and power. A boost converter (DC-DC) is used to maintain a steady voltage. The

boost converter receives the panel's output voltage. and maintain at certain level. In boost converter, instead of normal inductance, transformer is used as a inductance in order to prevent the system from the leakage reactance by providing Galvonic isolation. The diode in the boost converter avoids the partial shading even when the panel receives less amount of solar radiation. So the voltage from the panel is always maintained at a certain needed level. This diode is also used to avoid the returning current from the grid to the panel. Capacitor is used to store the voltage temperorily. The modified perturb and observe algorithm is used to monitor the maximum power point from the panel by incrementing or decrementing it. The output of MPPT is achieved using a MOSFET switch, resulting in a steady output voltage with no ripple.

The Practical bulk power system interface generator [1] are used to interconnect many power grids but they suffers from deregulation and conjestion and also they are more complex. Many synchronization techniques are suffer from double frequency oscillation[2-3] which can be rectified using the PLL based transformations.Adaptive Laguerre Filter [4] based techniques may suffer from accuracy due to correlation in the input and the reference signal. Second order sequence based algorithm [5] will not have feasible solution because of using too many loss functions.

The existing system uses DSTATCOMwith the grid connected system, which is also used to mitigate the power quality problems [6] . But it will suffer from the reactive power drop and initial cost is very high. The major problem faced by this technique is, it suffers from collapse in voltage, which leads to overvoltage problem. The Delta-Bar-Delta Neural-Based Control [7] technique for improving power efficiency suffers from a time delay in detecting frequency variance. Pseudo affine algorithm [8] based system results in echo path and limitation over the initial convergence period occurs due to the mitigation in the convergence speed of the system. 
Low voltage ride [9] in PV system will suffers from losses in power and this technique is vulnerable in tracking the balancing condition. Normalized adaptive Neural filter [10] in PV system using microgrid requires batteries to store the energy and also occupies more space and need frequent maintanence. The main drawback of this system is that, it suffers from Re-synchronization problem. Usage of net metering is another major issue. Novel adaptive Current Regulator [11] suffers from inaccurate feedback and regulation problems may occurs.Energy saving estimation in smart-grid [12] results in high production cost and analog meters must be replaced with the electronics meter. Weak grid interfaced PV system [13] where the value of impedance is high which may damages the system by producing overheating. HTF-based-higher-order adaptive control PV system [14] is robust and produces some noise signal. Support Vector Machine [15] based PV system are very sensitive to outliers and hinge loss occurs due to the misclassification of convex loss.

The proposed system deals with the Three phase inverter, where the gate signal is fed by a PWM generator regulated by SRF-PLL theory. The inverter's harmonics and reactive power are compensated using this principle, which is then fed to the distributing device. PI controller is used in order to normalize and minimize error signal form the system and it is a feedback controller. Here the theory compares the actual real and reactive power with the reference power using Park and Clarke transformation. They have a good static and dynamic characteristics under a wide range of frequency and also used in eliminating the double frequency oscillation.

\section{I. Design and Control Methodology:}

\section{Boost converter design:}

To keep the voltage constant, a boost converter is used.An inductor is used to avoid the galvonic isolation which avoids the leakage reactance. A diode is used to keep the panel from returning current to the grid and to avoid partial shading of the device. A capacitor is used to store the energy temperorily. As a result, the boost converter is used to boost the voltage from the PV plate.

The output voltage equation is given by;

$V_{\text {OUT }}=\frac{V_{I N}}{1-K}$

The output current equation is given by;

$I_{\text {OUT }}=\frac{I_{I N}}{1-K}$

The output load resistance of the converter is given by;

$R_{\text {OUT }}=V_{\text {OUT }} /_{I_{\text {OUT }}}$

The inductance value is calculated by using the following formulas

$L=\frac{(1-K) K R_{O U T}}{2 F}$

The MPPT algorithm is used to calculate the maximum point in a boost converter.

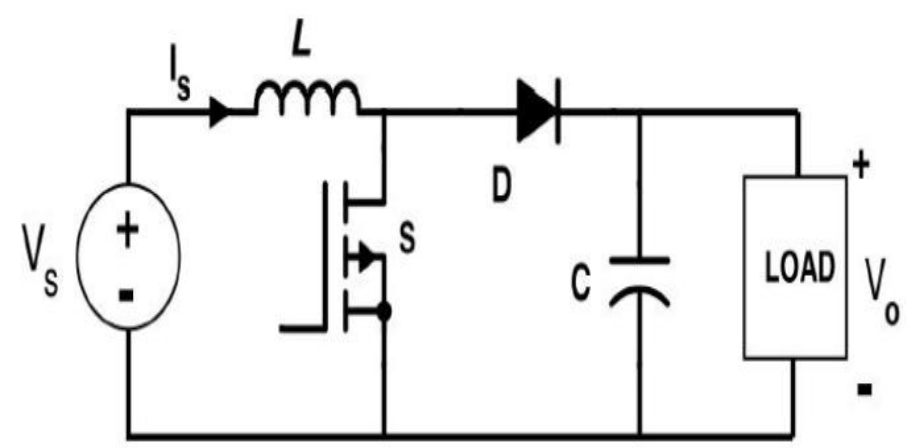

Figure 1.1: Circuit Diagram of Boost Converter 


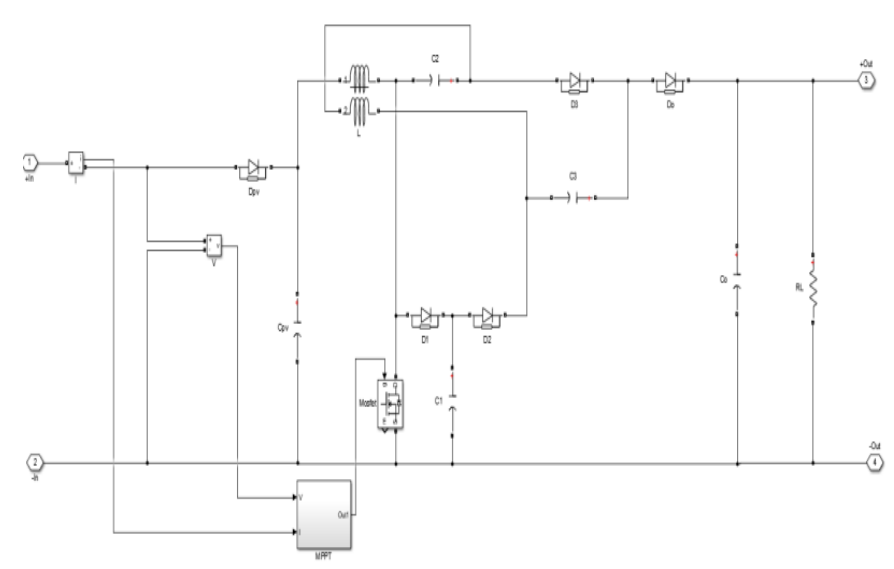

Figure 1.2: Simulation Diagram of Boost Converter

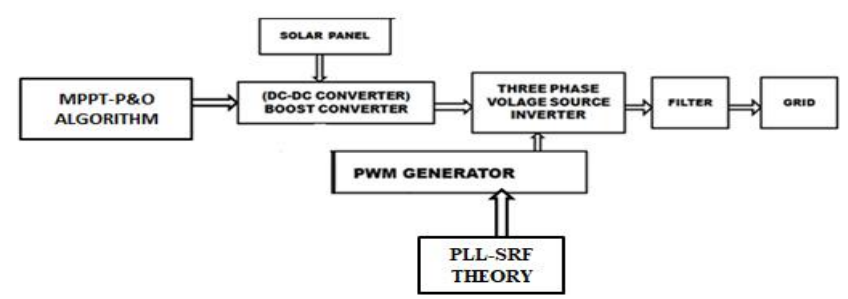

Figure1.3: Block Diagram of Modified P\&O Based Grid Connected System

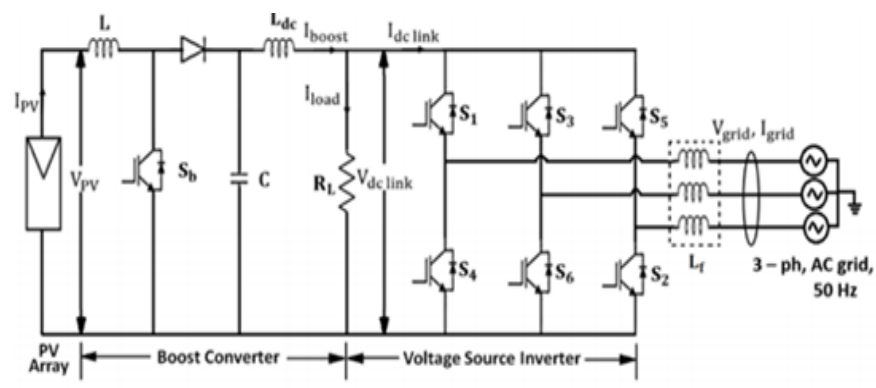

Figure 1.4: Circuit Diagram of Grid Connected Photovoltaic System

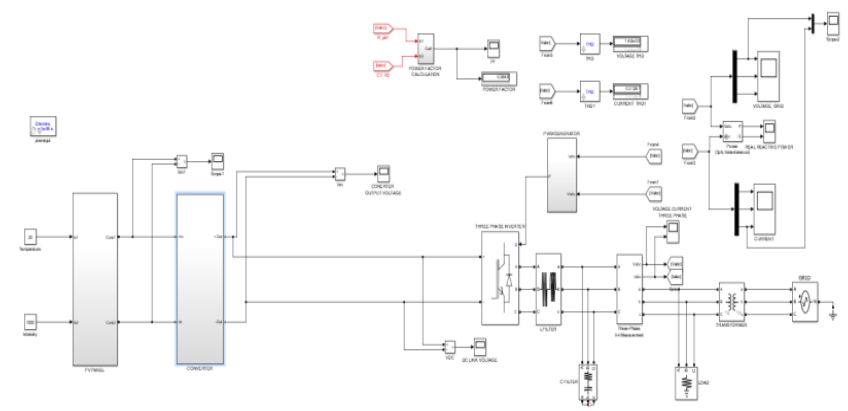

Figure1.5: Simulation Diagram For Modified P\&O Based Grid Connected PV System. 


\section{Modified P\&O Algorithm:}

By comparing the actual given voltage with the previous output voltage when incrementing or decrementing the duty cycle, the modified Perturb and Observe (P\&O) Algorithm is used to monitor the maximum power point. Since the voltage from the panel is not constant, it is regulated by the $\mathrm{P} \& \mathrm{O}$ algorithm, which multiplies the current and voltage to generate the actual power. Thus this value gets stored in the memory which has been gets updated for every ten milliseconds. Thus the power before and after10 millisecondsare calculated. After knowing these two, the reference and actual power gets compared using the Algorithm. Here the relay switch is used to provide the $\mathrm{ON}$ and the OFF time.

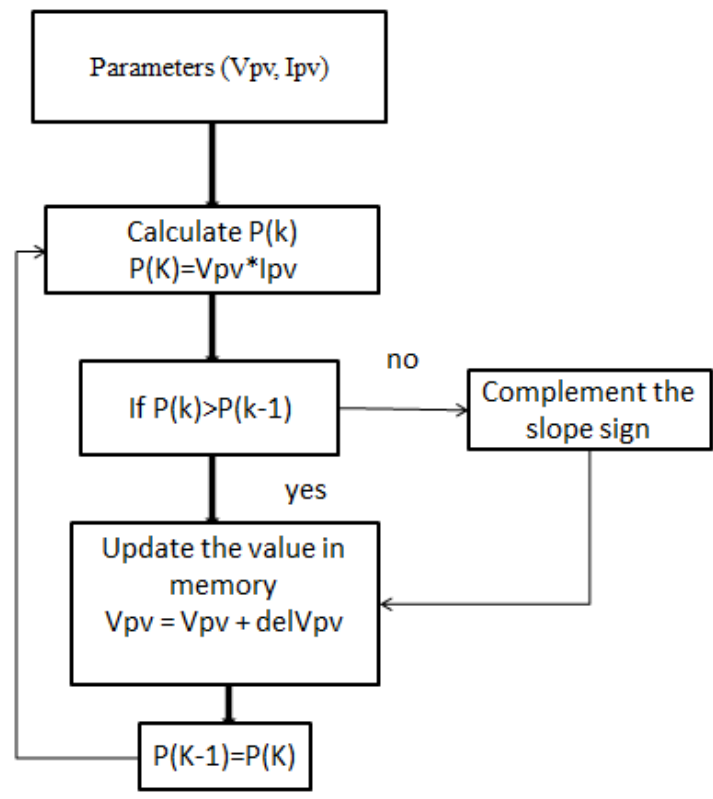

Figure 2.1: Block Diagram of Modified P\&O Algorithm

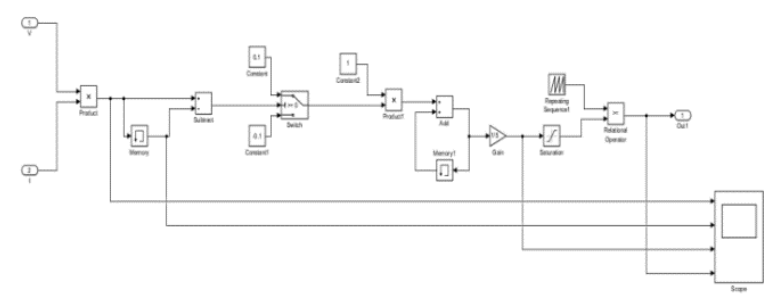

Figure 2.2: Simulation Diagram of Modified P\&O Algorithm

\section{Synchronous Reference frame theory-Phase Locked Loop:}

\section{1: Harmonic detection:}

Phase locked loop play a vital role in grid synchronization in implementing dq transformations. It provides a extremity of immunity against the harmonics producing components, unbalancing, sag or swell in the voltage waveform, notches and many other distortion type happens in the input signal.

The Phase Lock Loop (PLL) is used to calculate the phase angle () from the grid voltage's angular frequency (). In a two-stage transformation process, the grid voltages $\mathrm{Va}, \mathrm{Vb}$, and $\mathrm{Vc}$ are transformed into dq frames.ie., Park and Clarke transformation. That is, abc to $\alpha \beta$ frame to dq reference frame.

$$
\begin{aligned}
W_{1}= & \sin \omega \mathrm{t} ; \\
& W_{2}=-\cos \omega \mathrm{t} ;
\end{aligned}
$$

abc to $\alpha \beta$ transformation:

Clarke transformation involves: 


$$
\begin{aligned}
& X_{\alpha}=X_{A}-\frac{1}{2}\left(X_{B}+X_{C}\right) ; \\
& X_{\beta}=2 / 3\left(X_{B}-X_{C}\right) ;
\end{aligned}
$$

The voltage equation is given by

$V_{a}=V_{s} \sin \omega \mathrm{t}$

$V_{b}=V_{s} \sin (\omega \mathrm{t}-120)$;

$V_{c}=V_{s} \sin (\omega \mathrm{t}+120)$;

The transformation equation is as follows;

$V_{\alpha}=\frac{3}{2} V_{s} \sin \omega \mathrm{t}$

$V_{\beta}=-\frac{2}{3} V_{s} \cos \omega \mathrm{t}$

$\alpha \beta$ to dq transformation:

Park transformation includes;

$$
\begin{aligned}
& V_{d}=\frac{2}{3} V_{s} \cos \left(\left(\omega^{\prime}-\omega\right)\right) \mathrm{t} ;-----\cdot--\cdot--\cdot---- \\
& V_{q}=\frac{2}{3} V_{s} \sin \left(\left(\omega^{\prime}-\omega\right)\right) t
\end{aligned}
$$

The active voltage and current are in phase with the grid voltage and current using this principle.In order to make them in phase, at first there is a need to generate a reference signal and that signal must be in phase with the actual voltage and current and their magnitude must between +1 and -1 . And this signal is produced by the PLL. Similarly, when reactive power must be sent to the grid, a PLL must be used to produce a signal that is out of step with the real voltage.

PI controller is used to make the reference value to zero and a unit delay block is used to hold and delay the input by the some specified sample period. This block accept a single input and generate a single output. In steady state this theory makes the $\mathrm{q}$ axis component equal to the zero axis components.

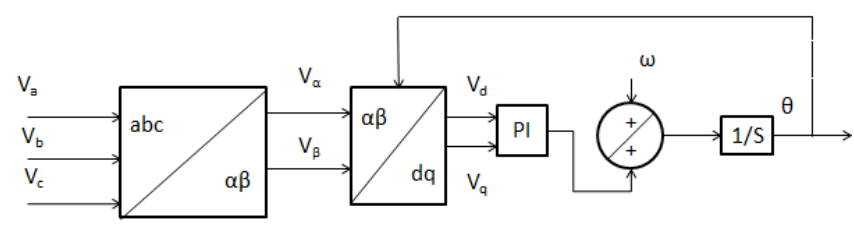

Figure 3.1.1: Block Diagram of SRF-PLL Theory Used in the Grid Connected System

To calculate the active current and the reactive current, the load equation must be calculated by using the following equation;

$$
\left.\left.\left.i_{l}=i_{p}(1-\cos 2 \omega t)+i_{q} \sin 2 \omega t+2 i_{k}\left(-\cos [k+1) \omega t+\Phi_{k}\right)\right]+\cos [k+1) \omega t+\Phi_{k}\right)\right]
$$

$i_{l}-i_{p}=i_{q}+i_{h}$

The harmonic current equation is given by;

$i_{h}=2 i_{n} \sin \mathrm{k} \omega \mathrm{t}+\Phi_{k}$

Thus the active and reactive current of the system is calculated as follows:

$\left.\left.\left.\left.i_{p}=2 i_{l} \sin \omega t-i_{q} \sin 2 \omega t+2 i_{k}\left(-\cos [k+1) \omega t+\Phi_{k}\right)\right]+\cos [k+1) \omega t+\Phi_{k}\right)\right]\right)$; (3.1.15)

$\left.\left.\left.\left.i_{q}=2 i_{l} \sin \omega t-i_{p} \sin 2 \omega t+2 i_{k}\left(-\cos [k+1) \omega t+\Phi_{k}\right)\right]+\cos [k+1) \omega t+\Phi_{k}\right)\right]\right) ;$ (3.1.16) 


\subsection{Computation of phase and quadrature voltage}

components:

$V_{r a}=\frac{2}{3}\left(V_{a b}+V_{b c}\right)$

$V_{r b}=\frac{1}{3}\left(V_{a b}+V_{b c}\right)$

$V_{r c}=\frac{1}{3}\left(-V_{a b}-V_{b c}\right)$

$V_{s}=V_{r a^{2}}+V_{r c^{2}}+V_{r b^{2}}$

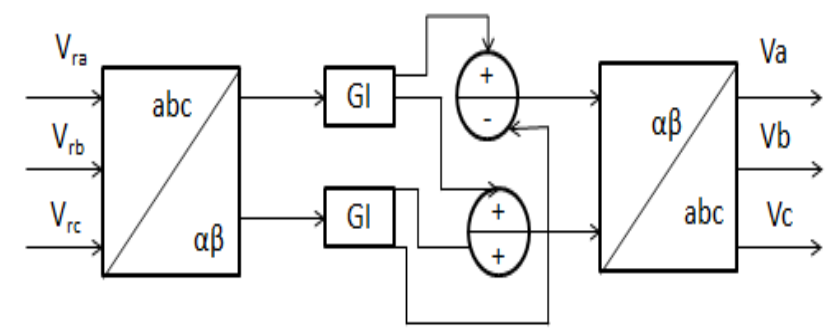

Figure 3.2.1: Block Diagram of Grid Integration

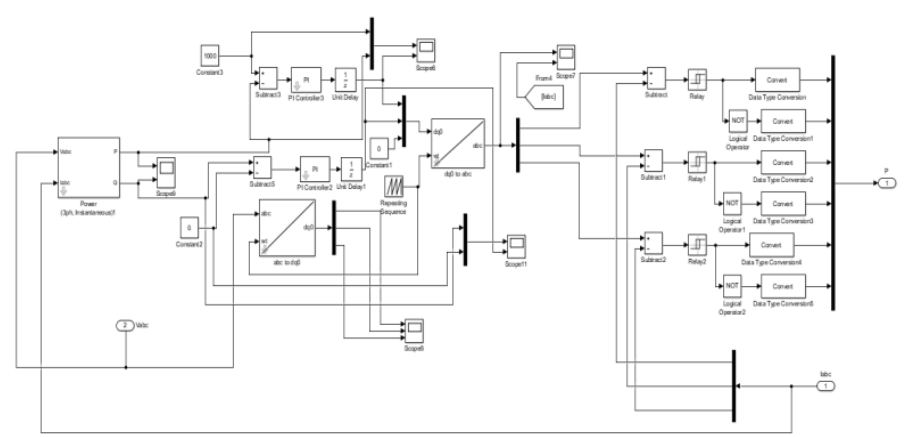

Figure: 3.2.2: Simulation Diagram of SRF-PLL used in Grid System

\section{Result:}

The voltage output of the solar PV panel and the voltage of the boost converter are calculated as follows. The solar panel generates 200 volts. The voltage obtained from the boost converter after using the maximum power tracking algorithm is $667.6 \mathrm{~V}$, as shown in figures 4.1 and 4.2 :

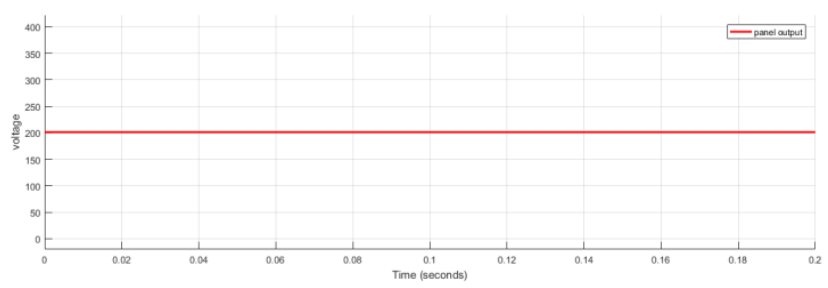

Figure4.1: Output Waveform of Solar Panel. 


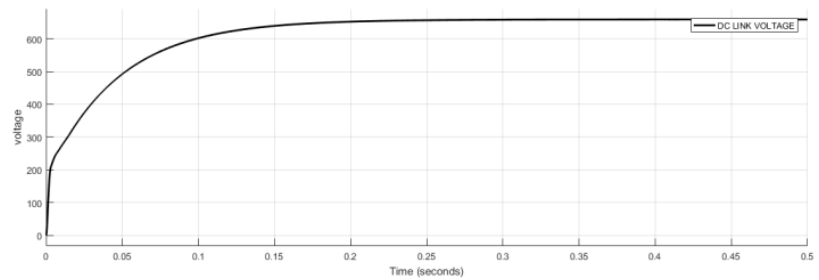

Figure4.2: Output Waveform of Boost Converter

The output waveform of the system after using the SRF-PLL theory for reactive power compensation is shown below in figure 4.3:

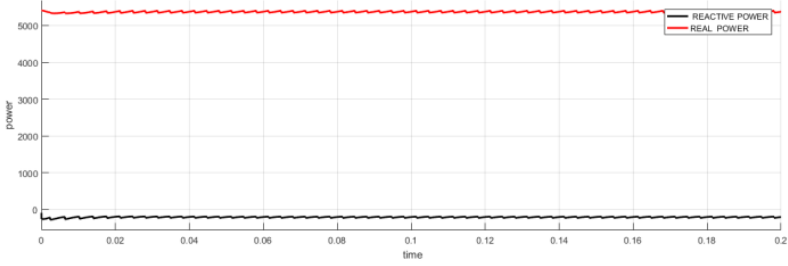

Figure4.3: Output Waveform of Real and Reactive Power

The output waveform of inverter current is shown in the figure 4.4, with some harmonic distortions

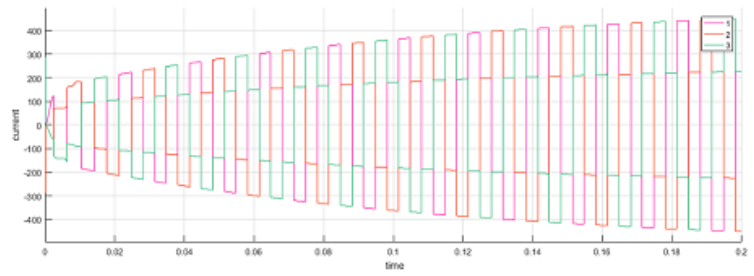

Figure4.4: Output Waveform of Inverter Current

The output waveform of the in phase grid voltage and current are shown below. The voltage obtained is $340 \mathrm{~V}$ as shown in figure 4.5 and 4.6 :

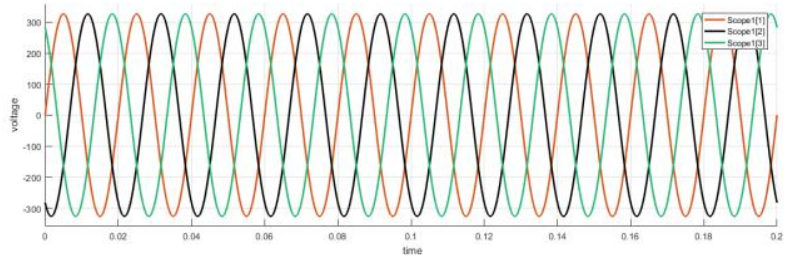

Figure4.5: Output Waveform of Grid Side Voltage

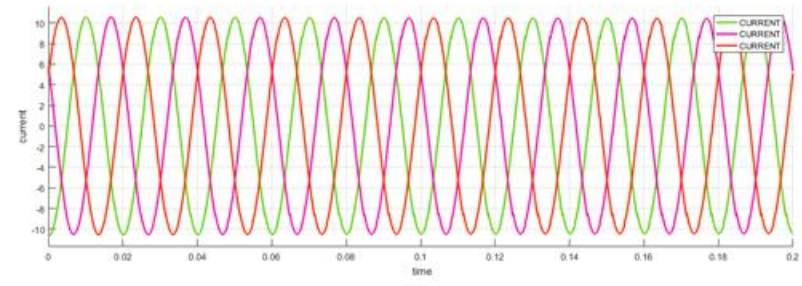

Figure 4.6: Output Waveform for Three Phase Grid Current

The power factor obtained by the system is shown as follows in figure 4.7: 


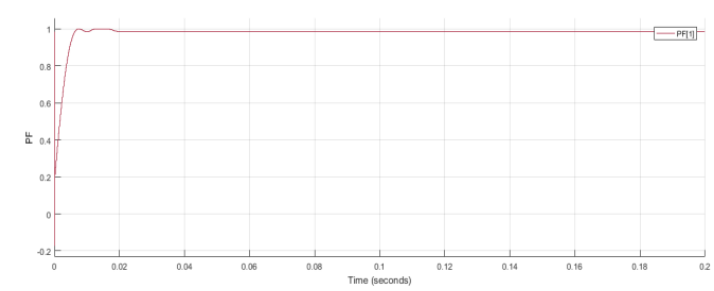

Figure 4.7: Power Factor of the Grid Connected PV System

The figure 4.8 shows the THD value of voltage in the system. Here the amount of THD obtained is shown for all phases.
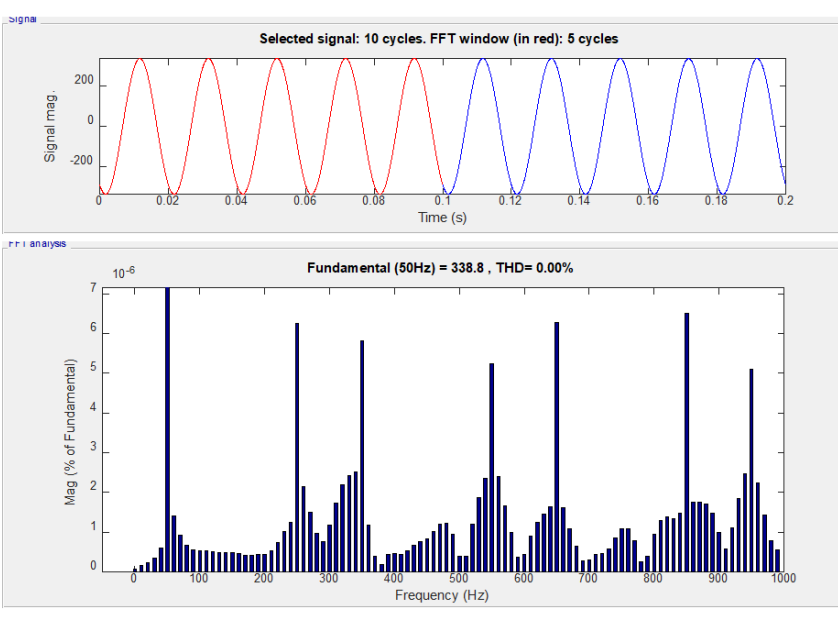

Figure 4.8: FFT Analysis of the VaPV System

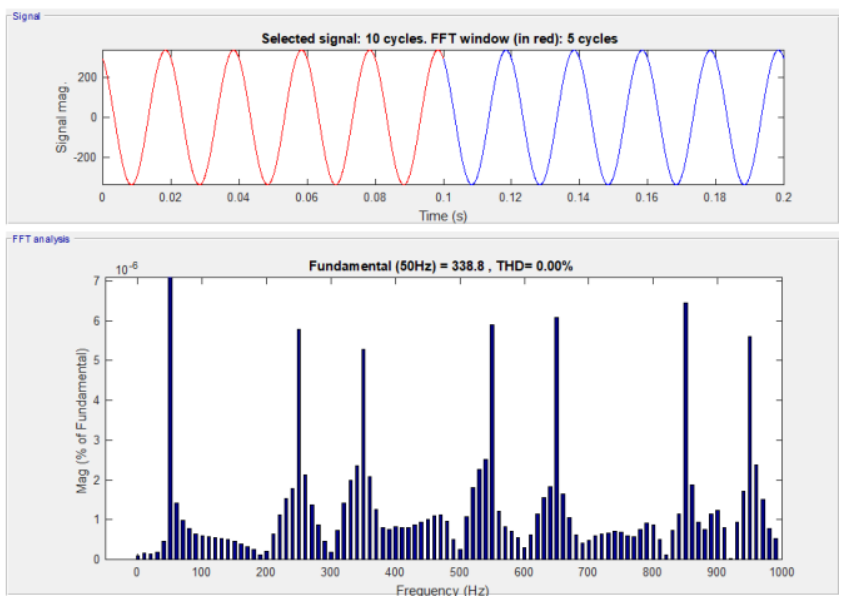

Figure 4.9: $\mathrm{THD}$ value for $\mathrm{Vb}$ Phase Component 


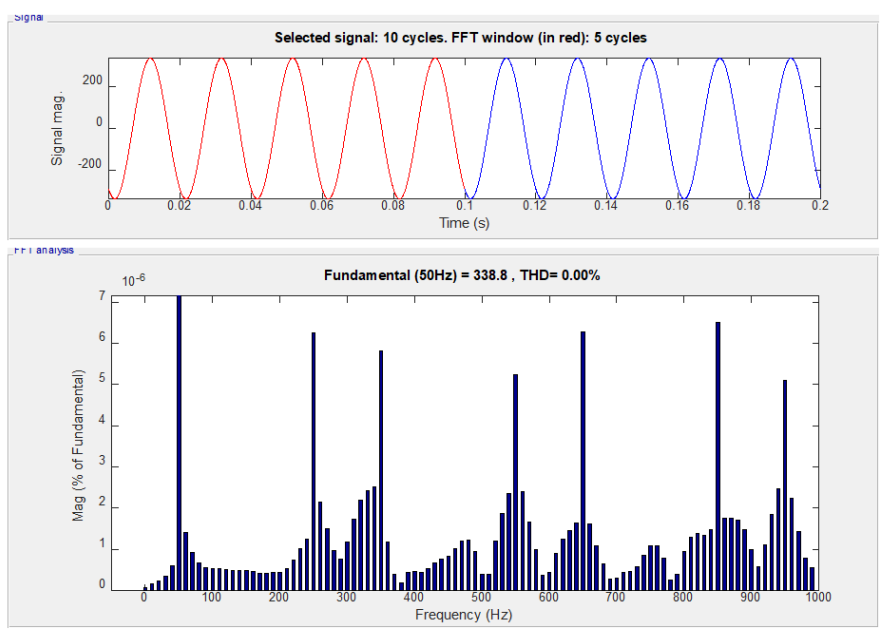

Figure 4.10: THD Value for Vc Phase Component

The THD value of load current is obtained as shown in the figure 4.11 and the THD value of current after using the SRF-PLL theory is also shown in the following figures:

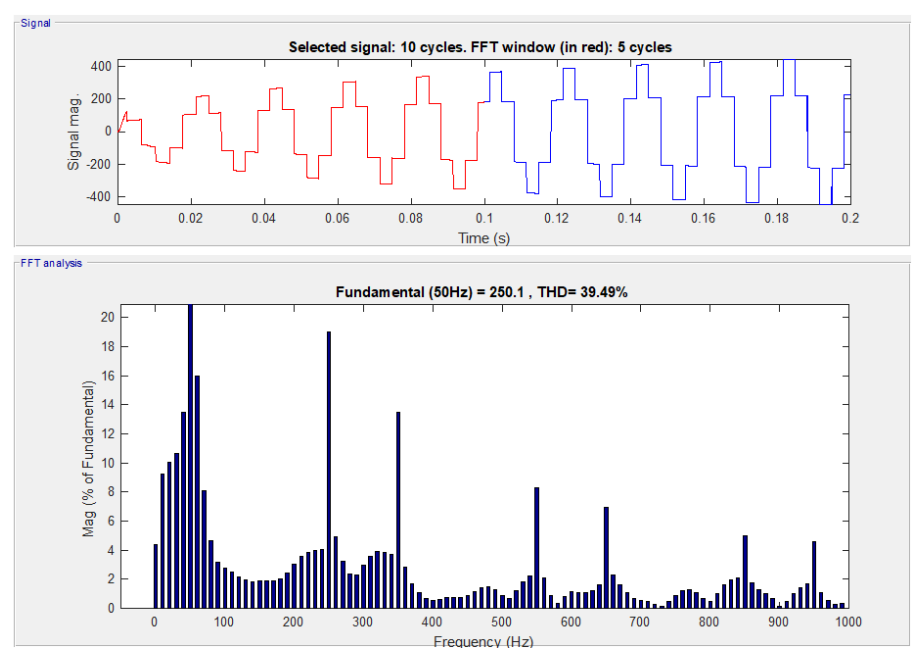

Figure 4.11: THD Value of Load Current

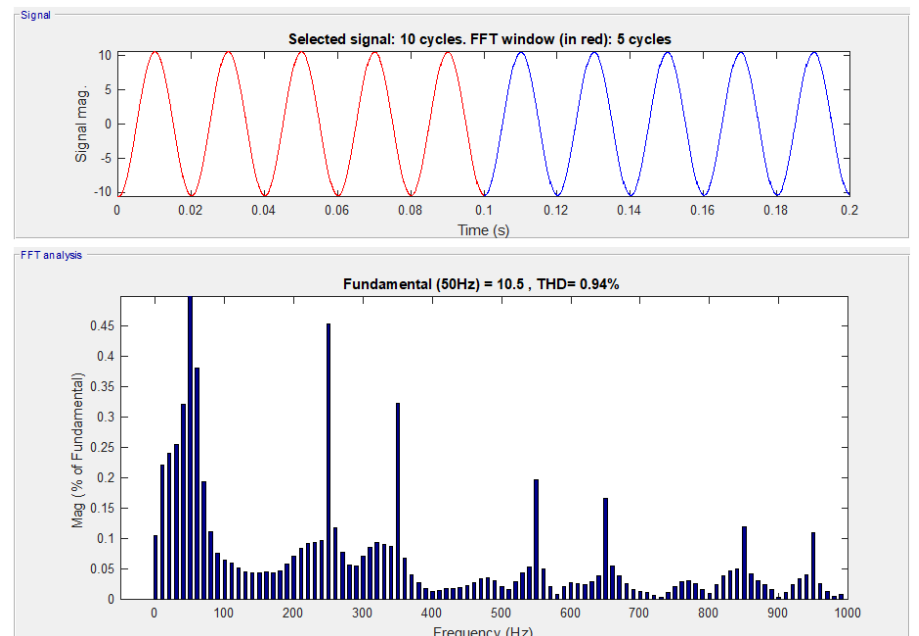

Figure 4.12: THD Value of Ia Phase Component 


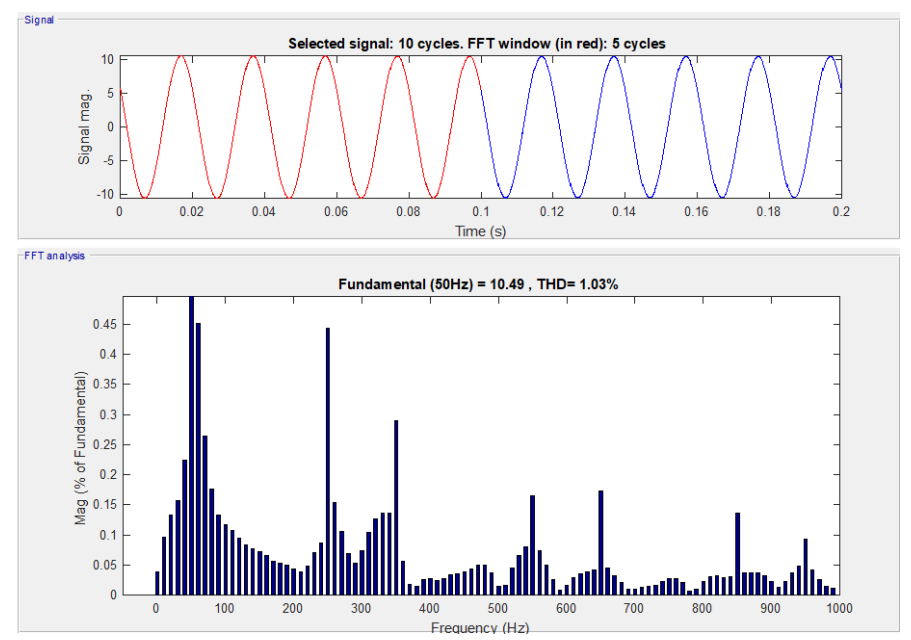

Figure4.13: THD Value of Ib Phase Component

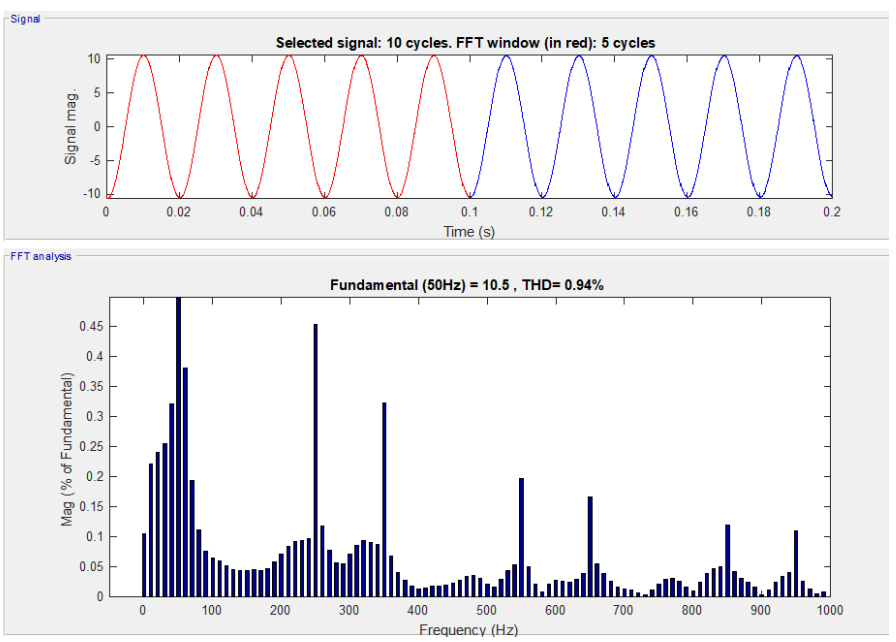

Figure4.14: THD Value of Ic Phase Component

Table 1: System Parameters Used

\begin{tabular}{|c|c|c|}
\hline \multicolumn{2}{|l|}{ SI.N } & Parameters \\
\hline 1 & Solar PV voltage & $200 \mathrm{v}$ \\
\hline 2 & $\begin{array}{c}\text { DC-DC converter } \\
\text { voltage }\end{array}$ & $667.67 \mathrm{v}$ \\
\hline 3 & Grid voltage & $340 \mathrm{v}$ \\
\hline 4 & Grid current & $340 \mathrm{v}$ \\
\hline 5 & Frequency & $50 \mathrm{~Hz}$ \\
\hline 6 & Inductance & $1 \mathrm{e}-3$ \\
\hline 7 & Capacitance & $4700 \mathrm{e}-6$ \\
\hline
\end{tabular}

\section{Conclusion:}

This paper evaluate a simulated analysis about reactive power and harmonics compensation by using SRF-PLL theory. The new sight is based on the use of a boost converter with a modified Perturb and Observe algorithm that detects the required maximum power output from the solar panel. The PI controller is used in detecting the error and also used in maintaining the power factor. Thus the simulation resultshows the better performance oncompensating reactive power and harmonics using the theory proposed.. 


\section{References}

Qiuhua Huang; Deepak Ramasubramanian; Vijay Vittal; Brian Keel; Jose Silva, Year: 2020, "Effect of accurate modelling of converter interfaced generation on a practical bulk power system", IET Generation, Transmission \& Distribution, vol. 14, no. 15, pp. 3108 - 3116.

Priyank Shah; Ikhlaq Hussain; Bhim Singh, Year: 2018, "Real-time implementation of optimal operation of single-stage grid interfaced PV system under weak grid conditions”, IET Generation, Transmission \& Distribution, vol. 12, no. 7, pp. 1631 - 1643.

Arun Kumar Verma; Bhim Singh, Year: 2018, "Harmonics and Reactive Current Detection of a Grid-Interfaced PV Generation in a Distribution System", IEEE Transactions on Industry Applications, vol. 54, no. 5, pp. 4786 - 4794.

Pavitra Shukl; Bhim Singh, Year: 2019, "Grid Integration of Three-Phase Single-Stage PV System Using Adaptive Laguerre Filter Based Control Algorithm Under Nonideal Distribution System”, IEEE Transactions on Industry Applications, vol. 55, no. 6, pp. 6193 - 6202.

Aakanksha Rajput; Neha Beniwal; Bhim Singh; Sukumar Mishra, Year: 2019, "Second-order sequence filter based control algorithm for single-phase grid interfaced solar PV system", IET Generation, Transmission \& Distribution, vol. 13, no. 12, pp. 2382 - 2390.

Amresh Kumar Singh; Shailendra Kumar; Bhim Singh, Year: 2020, "Solar PV Energy Generation System Interfaced to Three Phase Grid With Improved Power Quality", IEEE Transactions on Industrial Electronics, vol. 67, no. 5, pp. $3798-3808$.

Pavitra Shukl; Bhim Singh, Year: 2020, "Delta-Bar-Delta Neural-Network-Based Control Approach for Power Quality Improvement of Solar-PV-Interfaced Distribution System", IEEE Transactions on Industrial Informatics, vol. 16, no. 2, pp. $790-801$.

Nirav Patel; Nitin Gupta; Ajay Kumar; B. Chitti Babu, Year: 2020, "Pseudo affine projection assisted multitasking approach for power quality improvement in grid-interactive photovoltaic (PV) system, IET Power Electronics, vol. 13, no. 13, pp. 2905 - 2916.

Priyank Shah; Bhim Singh, Year: 2020, "Low-voltage ride-through operation of grid interfaced solar PV system enabling harmonic compensation capabilities", IET Renewable Power Generation, vol. 14, no. 12, pp. 2100 2113.

Shubhra Shubhra; Bhim Singh, Year: 2020, "Three-Phase Grid-Interactive Solar PV-Battery Microgrid Control Based on Normalized Gradient Adaptive Regularization Factor Neural Filter", IEEE Transactions on Industrial Informatics, vol. 16, no. 4, pp. $2301-2314$.

V. Narendra Kumar; Narendra Babu P.;R. Kiranmayi; Pierluigi Siano; Gayadhar Panda, Year: 2020, "Improved Power Quality in a Solar PV Plant Integrated Utility Grid by Employing a Novel Adaptive Current Regulator", IEEE Systems Journal, vol. 14, no. 3, pp. 4308 - 4319.

Shailendra Singh;Shiv P. Singh, Year: 2018, "Energy saving estimation in distribution network with smart gridenabled CVR and solar PV inverter", IET Generation, Transmission \& Distribution, vol. 12, no. 6, pp. 1346 1358.

TripurariNath Gupta;ShadabMurshid;Bhim Singh, Year: 2019, "Power quality improvement of single phase weak grid interfaced hybrid solar PV and wind system using double fundamental signal extracter-based control”, IET Generation, Transmission \& Distribution, vol. 13, no. 17, pp. 3988 - 3998.

Vandana Jain;IkhlaqHussain;Bhim Singh, Year: 2019, “A HTF-Based Higher-Order Adaptive Control of SingleStage Grid-Interfaced PV System”, IEEE Transactions on Industry Applications, vol. 55, no. 2, pp. 1873 1881.

Hamid RezaBaghaee;DraganMlakić;SreteNikolovski;TomislavDragicević, Year: 2020, "Support Vector Machine-Based Islanding and Grid Fault Detection in Active Distribution Networks", IEEE Journal of Emerging and Selected Topics in Power Electronics, vol. 8, no. 3, pp. 2385 - 2403.

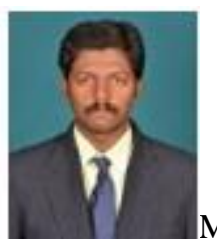

M. Balasubramanian received the B.E degree in Electrical and Electronics Engineering in 2006 and also received his M.E degree (Power Systems) in 2009 from Anna University, Chennai, India. He is currently working as Assistant Professor in Government College of Engineering, Tirunelveli, India. His area of interests includes active power filters, power quality improvement in distribution systems, renewable energy systems. 
MIN C.Priyadharshini received the B.E degree in Electrical and Electronics Engineering from Anna University, Chennai, India in 2019. She is currently a PG scholar in Power Electronics and Drives from Government College of Engineering, Tirunelveli, India. Her research interests include power quality, power converter topologies and their control 